Case Reports in
Gastroenterology
Case Rep Gastroenterol 2020;14:361-366

DOI: $10.1159 / 000508436$

Published online: July 28, 2020
(C) 2020 The Author(s)

Published by S. Karger AG, Basel www.karger.com/crg

This article is licensed under the Creative Commons Attribution-NonCommercial 4.0 International License (CC BY-NC) (http://www.karger.com/Services/OpenAccessLicense). Usage and distribution for commercial purposes requires written permission.

\title{
A Rare Manifestation of a Bleeding Tubulovillous Duodenal Polyp Presenting as an Upper Gastrointestinal Hemorrhage
}

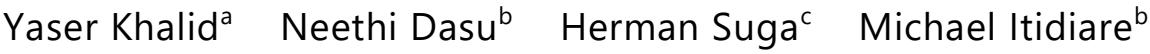 \\ Richard Walters ${ }^{\mathrm{b}}$ \\ aDivision of Internal Medicine, Memorial Healthcare System, Davie, FL, USA; ${ }^{b}$ Division of \\ Gastroenterology, Rowan School of Osteopathic Medicine, Jefferson Health System, \\ Stratford, NJ, USA; 'Division of Internal Medicine, Rowan School of Osteopathic Medicine, \\ Jefferson Health System, Stratford, NJ, USA
}

\section{Keywords}

Gastrointestinal hemorrhage · Anemia · Tubulovillous adenoma · Duodenal polyp ·

Pedunculated polyp

\begin{abstract}
Duodenal polyps have been reported in $<1.5 \%$ of individuals who undergo esophagogastroduodenoscopy (EGD). We present a case of a 76 -year-old male with recurrent hematemesis who was found to have an intestinal-type, pedunculated tubulovillous adenoma in the descending duodenum. An isolated occurrence of nonampullary sporadic duodenal adenoma is a rare finding. Presentation as an upper gastrointestinal hemorrhage is also extremely uncommon. Our patient's polyp was pedunculated, which is atypical, because most sporadic duodenal adenomas are morphologically flat or sessile. The purpose of this case is to present a rare cause of upper gastrointestinal bleeding and to depict characteristics of an isolated duodenal tubulovillous adenoma and its treatment options.




\section{Case Reports in Gastroenterology}

Case Rep Gastroenterol 2020;14:361-366

DOI: $10.1159 / 000508436$

c) 2020 The Author(s). Published by S. Karger AG, Basel www.karger.com/crg

Khalid et al.: A Bleeding Tubulovillous Duodenal Polyp Presenting as Gastrointestinal Hemorrhage

\section{Introduction}

Duodenal polyps are a group of polyps that are uncommon to find on endoscopic evaluation. They have been reported in $0.3-1.5 \%$ of individuals who undergo upper endoscopy; therefore, they are considered a rare finding [1]. They are histologically classified according to mucin phenotype into intestinal (89.1\%) and gastric type (10.9\%); the intestinal-type polyps are morphologically subdivided into tubular and tubulovillous adenomas. These polyps grossly present as sessile or pedunculated polyps, nodules, excrescences, or subtle abnormalities of mucosa; they can be located either in the duodenal bulb, ampullary region, or distal duodenum [2]. Duodenal polyps are generally benign and carry a low probability for malignant transformation, and around $90 \%$ are nonneoplastic [3]. As endoscopic technology has advanced, the incidence of duodenal polyps has increased. Patients present with symptoms of dyspepsia, abdominal discomfort, mechanical obstruction, and sometimes jaundice. Other atypical and rare symptoms include hematemesis, which was seen in this case [2].

\section{Case Report}

A 76-year-old male from a long-term care facility presented with symptoms of feeling "off" and having increased respiratory secretions. He also complained of coughing, wheezing, and dyspnea. His past medical history included systolic congestive heart failure status-postautomatic implantable cardioverter-defibrillator, chronic kidney disease, chronic obstructive pulmonary disease, paroxysmal atrial fibrillation, hypertension, rheumatoid arthritis, prostate cancer, and a brain mass. On physical examination, he appeared frail and his abdomen was soft and nontender with normal bowel sounds. He also had marked basilar rhonchi on the auscultation of his chest. He was initially placed on bi-level positive airway pressure for respiratory support. However, his mental status continued to decline, and he required intubation with admission to the intensive care unit (ICU) for increasing oxygen requirements and respiratory distress. He was found to have acute hypoxemic respiratory failure secondary to bacterial pneumonia and an acute congestive heart failure exacerbation, which was treated with intravenous diuretics and antibiotics. Gastroenterology was initially consulted because the patient had an episode of coffee-ground hematemesis that was noticed when the nurse was checking his residuals after tube feeding. His hemoglobin was $9.9 \mathrm{~g} / \mathrm{dL}$, which was his baseline level. He was hemodynamically stable and thus required no acute endoscopic intervention by gastroenterology. His hematemesis was thought to be secondary to apixaban and aspirin which he was using for coronary artery disease and paroxysmal atrial fibrillation, and thus his apixaban was stopped. Gastroenterology was re-consulted when the patient's hemoglobin decreased to $6.6 \mathrm{~g} / \mathrm{dL}$, and orogastric lavage revealed $1 \mathrm{~L}$ of coffee-ground emesis. At that time, the patient underwent an emergent esophagogastroduodenoscopy (EGD) which revealed a 10-mm pedunculated polyp in the proximal duodenum with active bleeding (Fig. 1, 2). The polyp was resected with hot snare and clipped twice. In addition to this polyp, there was a nonbleeding 4-mm sessile-appearing polyp slightly distally, which was removed with hot snare polypectomy. After EGD, the patient's hematemesis resolved, and his hemoglobin level stabilized back to baseline. However, his acute congestive heart failure and bacterial pneumonia progressed and worsened his respiratory failure. Thus, his family opted for comfort measures and no further interventions. The biopsy of the polyp tissue revealed a tubulovillous adenoma with minute foci of high-grade dysplasia (Fig. 3). 


\section{Case Reports in Gastroenterology}

\begin{tabular}{l|l}
\hline Case Rep Gastroenterol 2020;14:361-366 \\
\hline DOI: 10.1159/000508436 & $\begin{array}{l}\text { ○ 2020 The Author(s). Published by S. Karger AG, Basel } \\
\text { www.karger.com/crg }\end{array}$ \\
\hline
\end{tabular}

Khalid et al.: A Bleeding Tubulovillous Duodenal Polyp Presenting as Gastrointestinal Hemorrhage

\section{Discussion}

Our patient had a pedunculated, intestinal-type tubulovillous adenoma. Nonampullary sporadic duodenal adenomas are those which arise in patients without a known polyposis syndrome, such as familial adenomatous polyposis or Gardner's syndrome [4]. Isolated occurrence of such adenomas is a rare finding and presentation as an upper gastrointestinal bleed is even rarer [5]. Most duodenal polyps are benign, but our patient presented with a malignant subtype. Our patient's neoplastic pedunculated polyp was identified in the second portion of the duodenum, which is another atypical and unusual occurrence, because the majority of sporadic duodenal adenomas are flat or sessile [4]. The risk of carcinoma is greater for ampullary adenomas and increases with the size of adenoma [4]. Adenomas that are larger than $20 \mathrm{~mm}$, or those that have high-grade dysplasia, have a higher rate of progression to adenocarcinoma (approximately 54.5\%) [4]. This patient's polyp was $10 \mathrm{~mm}$, but with high-grade dysplasia the odds of being malignant are higher, as was seen on biopsy.

Duodenal adenocarcinomas have a significantly higher expression of gastric markers, such as MUC5AC and MUC6 as well as a higher MIB-1 index. Malignant polyps usually have increased depth of mucus invasion. Aside from biopsy, the likelihood of malignancy can be determined while removing the polyp and performing a lift sign, to evaluate if the polyp can be easily lifted from the mucosa's surface. A poor lift sign indicates a higher risk of malignancy; this was seen in this case.

Duodenal polyps typically present with the following symptoms: epigastric pain, jaundice, dyspepsia, and/or weight loss [1]. None of these symptoms were seen in our case so it is unclear how long the patient had this duodenal polyp. Most patients are asymptomatic and very few present primarily with an upper gastrointestinal bleed, as seen in this case.

There are currently no definitive guidelines on how a duodenal polyp should be resected. Further studies are needed to assess techniques that can decrease mortality and prevent recurrence. Our patient died during the same hospitalization, but if he survived, it would have been essential for him to follow up for a repeat EGD within 6 months, in order to monitor the resection base of the polyp and to determine whether there was any recurrent neoplastic tissue [1].

EGD techniques that are currently used for intervention are endoscopic snare and electrocautery, which were successful in this case as the patient's hematemesis resolved. The use of EGD can also have complications, which include perforation, further bleeding, and sedation from anesthesia. However, no complications were seen following EGD in this case.

\section{Conclusion}

Duodenal polyps are a rare occurrence. Most are benign. We presented a case of a 76year-old male with recurrent hematemesis and anemia who was found to have a duodenal polyp. This is a unique case due to the patient's presenting symptoms of an upper gastrointestinal hemorrhage with findings of a pedunculated tubulovillous duodenal adenoma with highgrade dysplasia. Further guidelines on how to manage malignant tubulovillous adenomas may prove beneficial, but pedunculated polyps should be resected and biopsied. EGD surveillance within 6 months is recommended because nonampullary sporadic adenomas have been linked to an increased risk of colorectal neoplasia [4]. It is also important for practitioners to keep in mind rarer causes of upper gastrointestinal bleeding. 


\section{Case Reports in Gastroenterology}

\begin{tabular}{l|l}
\hline Case Rep Gastroenterol 2020;14:361-366 \\
\hline DOI: 10.1159/000508436 & $\begin{array}{l}\text { ○ 2020 The Author(s). Published by S. Karger AG, Basel } \\
\text { www.karger.com/crg }\end{array}$ \\
\hline
\end{tabular}

Khalid et al.: A Bleeding Tubulovillous Duodenal Polyp Presenting as Gastrointestinal Hemorrhage

\section{Statement of Ethics}

Informed consent for publication was obtained from the patient's family member/POA (including publication of images).

\section{Conflict of Interest Statement}

The authors have no conflicts of interest to declare.

\section{Funding Sources}

The authors have no funding sources to disclose.

\section{Author Contributions}

Yaser Khalid and Neethi Dasu: conception of the work, data analysis and interpretation, critical revision of the article, and final approval of the version to be published. Richard Walters: conception of the work, data analysis and interpretation, and critical revision of the article. Michael Itidiare: data collection, data analysis and interpretation, and critical revision of the article. Herman Suga: data collection, data analysis and interpretation, and drafting the article. All authors approved the final version of the manuscript.

\section{References}

1 Jepsen JM, Persson M, Jakobsen NO, Christiansen T, Skoubo-Kristensen E, Funch-Jensen P, et al. Prospective study of prevalence and endoscopic and histopathologic characteristics of duodenal polyps in patients submitted to upper endoscopy. Scand J Gastroenterol. 1994 Jun;29(6):483-7.

2 Collins K, Ligato S. Duodenal Epithelial Polyps: A Clinicopathologic Review. Arch Pathol Lab Med. 2019 Mar;143(3):370-85.

3 Lee CH, Shingler G, Mowbray NG, Al-Sarireh B, Evans P, Smith M, et al. Surgical outcomes for duodenal adenoma and adenocarcinoma: a multicentre study in Australia and the United Kingdom. ANZ J Surg. 2018 Mar;88(3):E157-61.

4 Basford PJ, Bhandari P. Endoscopic management of nonampullary duodenal polyps. Therap Adv Gastroenterol. 2012 Mar;5(2):127-38.

5 Murray MA, Zimmerman MJ, Ee HC. Sporadic duodenal adenoma is associated with colorectal neoplasia. Gut. 2004 Feb;53(2):261-5. 
Case Reports in Gastroenterology
Case Rep Gastroenterol 2020;14:361-366

DOI: $10.1159 / 000508436$

(c) 2020 The Author(s). Published by S. Karger AG, Basel www.karger.com/crg

Khalid et al.: A Bleeding Tubulovillous Duodenal Polyp Presenting as Gastrointestinal Hemorrhage

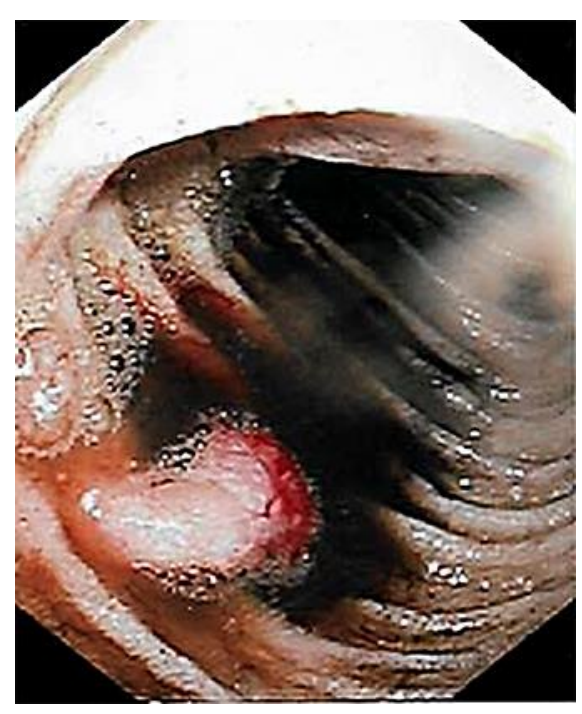

Fig. 1. EGD revealing a 10-mm pedunculated polyp in the proximal duodenum with active bleeding.

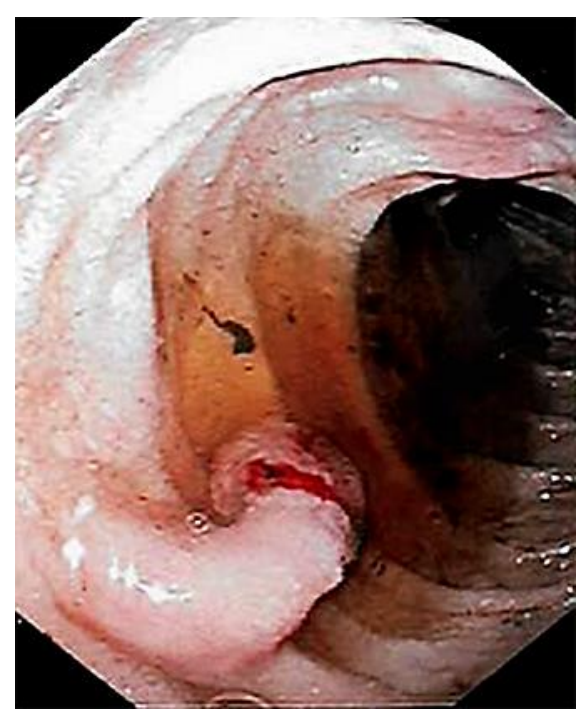

Fig. 2. A 10-mm pedunculated polyp in the proximal duodenum with active bleeding. 
Case Reports in Gastroenterology
Case Rep Gastroenterol 2020;14:361-366

DOI: $10.1159 / 000508436$ (c) 2020 The www.karger.com/crg

Khalid et al.: A Bleeding Tubulovillous Duodenal Polyp Presenting as Gastrointestinal Hemorrhage

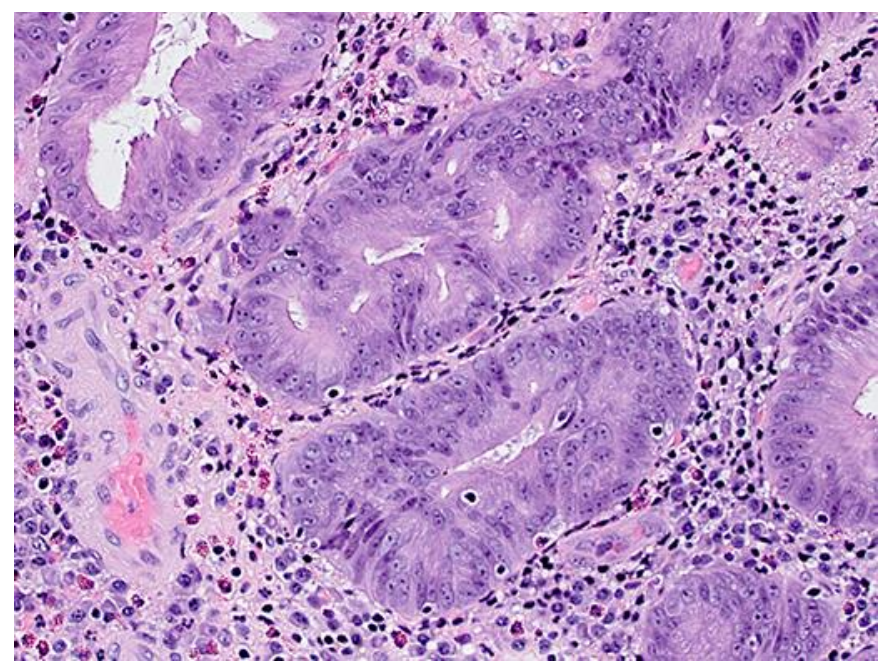

Fig. 3. Focal $20 \times$ representation of tubulovillous adenoma with minute foci of high-grade dysplasia. 